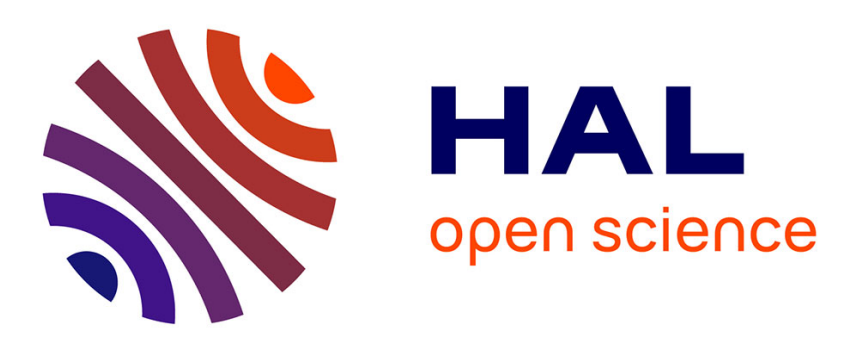

\title{
Manual wheelchair's turning resistance: swivelling resistance parameters of front and rear wheels on different surfaces
}

Constantin Fallot, Joseph Bascou, Hélène Pillet, Christophe Sauret

\section{To cite this version:}

Constantin Fallot, Joseph Bascou, Hélène Pillet, Christophe Sauret. Manual wheelchair's turning resistance: swivelling resistance parameters of front and rear wheels on different surfaces. Distability and Rehabilitation: Assistive Technology, 2019, pp.1-8. 10.1080/17483107.2019.1675781 . hal-02565384

\author{
HAL Id: hal-02565384 \\ https://hal.science/hal-02565384
}

Submitted on 6 May 2020

HAL is a multi-disciplinary open access archive for the deposit and dissemination of scientific research documents, whether they are published or not. The documents may come from teaching and research institutions in France or abroad, or from public or private research centers.
L'archive ouverte pluridisciplinaire HAL, est destinée au dépôt et à la diffusion de documents scientifiques de niveau recherche, publiés ou non, émanant des établissements d'enseignement et de recherche français ou étrangers, des laboratoires publics ou privés. 


\title{
Manual wheelchair's turning resistance: swivelling resistance parameters of front and rear wheels on different surfaces
}

\author{
Constantin Fallot ${ }^{\mathrm{a}, \mathrm{b}}$, Joseph Bascou ${ }^{\mathrm{a}, \mathrm{b}} \mathbb{D}$, Hélène Pillet ${ }^{\mathrm{a}} \mathbb{D}$ and Christophe Sauret ${ }^{\mathrm{a}} \mathbb{D}$ \\ ${ }^{a}$ Institut de Biomécanique Humaine Georges Charpak, Arts et Métiers ParisTech, Paris, France; ${ }^{b}$ Institution Nationale des Invalides, Centre \\ d'Etudes et de Recherche sur l'Appareillage des Handicapés, Woippy, France
}

\begin{abstract}
Purpose: Daily locomotion with a manual wheelchair includes curvilinear movements. However, little is known about the resisting forces in play during turning manoeuvres where the wheels are generally both rolling and swivelling. This study aimed at quantifying the swivelling resistance parameters of several wheels on different surfaces and to evaluate the effect of the curvature radius on these parameters.

Materials and methods: A specific test bench was designed allowing the swivelling resistance parameters of a wheel rolling while swivelling to be determined. Seven wheels ( 3 front and 4 rear wheels), three surfaces (plywood, linoleum and carpet), two loads (25 and $45 \mathrm{~kg}$ ) and five curvature radii (from 0 to $0.4 \mathrm{~m}$ ) were tested through a full factorial design experiment.

Results: Results showed that the wheel type was the most influential factor on swivelling resistance parameters, followed by the surface and the curvature radius. The effect of the load on swivelling resistance parameters was found negligible when compared to the influence of other factors. A predictive model for swivelling resistance parameters of the different wheel/surface combinations was proposed, as a function of the curvature radius.

Conclusion: This study allowed the swivelling resistance parameters of different wheel/surface combinations to be quantified, as a function of the curvature radius of the wheel trajectory. Combined with data on rolling resistance, these data could now be used to assess energy losses during real life ambulation or to achieve more realistic behaviour in virtual rehabilitation environment.

> IMPLICATIONS FOR REHABILITATION

- Swivelling resistances are increased by carpet surfaces compared to tile surfaces.

- Conversely to rolling resistance, castors wheels are less prone to swivelling resistance than rear wheels

- The swivelling resistance of a wheel rolling while swivelling is decreased compared to a pure swivelling movement.

- Combined with data on rolling resistance, these data on swivelling resistance would allow energy loss during daily life activity to be determined or as input data for the control of wheelchair simulator in virtual environment used for rehabilitation.
\end{abstract}

\section{Introduction}

When walking capability is altered, a manual wheelchair (MWC) is frequently prescribed, allowing the person to recover some autonomy. In developed countries, about 3.6 million people in the United States in 2010 [1] and from 600,000 to 700,000 people in European countries such as France or the United Kingdom [2] use a MWC, i.e., between $1 \%$ and $2 \%$ of the populations. However, MWC locomotion is constraining for the upper limbs and many users report shoulder pain or injuries [3].

Besides, loads sustained by the shoulders were also reported to be related to shoulder pathology [4]. Among the different sources of shoulder loading, there is the MWC energy loss through rolling and turning resistances during daily life activities. Limiting MWC energy loss is thus an important topic that requires the ability to quantify both rolling and swivelling resistances. Also, because MWC often start to be used during adulthood, moving with a MWC needs to be learned. In order to facilitate skill

\section{KEYWORDS}

Resistance; swiveling;

surfaces; turn-

ing; wheelchair acquisition, rehabilitation programmes currently tend to introduce virtual environments, allowing various visual and/or haptic feedbacks [5-10]. However, to ensure skills transfer from virtual environments to life-like situations, the simulator should faithfully reproduce the real locomotion in the field, including resistance due to MWC energy loss.

Rolling resistance was extensively investigated [11-21] and quantitative data are already available in the literature for the prediction of rolling resistance depending on the type of wheel and floor [22]. Conversely, turning resistance was less studied although turning manoeuvres are regularly performed during daily activities. Some authors $[19,23]$ showed that the turning moment, which is required to create an angular acceleration of the MWC, increases with both the MWC-and-user mass and its antero-posterior distribution (i.e., by increasing the mass moments of inertia; e.g., by moving the seat forward with respect to the rear wheels). They also pointed out that at least half of the turning moment was due to 
non-inertial forces, i.e., wheel rolling and swivelling resistances. Some studies have already qualitatively clarified the effect of the wheel type [11] and tire inflation [24], but few quantitative data are currently available to assess the turning resistance. Some rare studies quantified the torque of wheel swivelling resistance in the specific case of a pure swivelling motion [11,24,25]. Kauzlarich et al. [25] attempted to consider the swivelling resistance of a wheel combining rolling and swivelling motions (Figure 1), which is the most commonly encountered situation during MWC turning manoeuvres and concluded that the wheel swivelling resistance decreases when the wheel is rolling while swivelling. More recent exploratory works dealing with the modelling of the turning motion of a MWC $[15,26]$ also led their authors to believe that actual swivelling resistance parameters should be from two to five times lower than those used in their simulations (derived from literature data of $[11,25]$ ) to be consistent with experimental data [27]. Finally, another recent exploratory work, using a robotic device, reported a decrease of the total MWC swivelling resistance from 16 to $2 \mathrm{Nm}$ when the curvature radius was increased from 0.2 to $1.8 \mathrm{~m}$ [20]. However, neither the respective contributions of front and rear wheels, nor the effect of different wheels and surfaces were quantified in all these studies. As a consequence, it is still not possible to predict the effects of different sets of wheel types on different surfaces when the loading conditions of the MWC are modified (i.e., depending on the subject and MWC total mass and centre of mass location).

In order to assess the energy loss during MWC locomotion, the knowledge of swivelling resistance parameters values for various wheel/surface combinations and with respect to the turning curvature radius is preliminary necessary. The literature analysis reveals a lack of quantitative data on these swivelling resistance parameters. To fill this lack of knowledge, the goal of this study was to quantify experimentally the swivelling resistance parameters of various typical wheels and floor surfaces according to the turning curvature radius.

\section{Materials and methods}

\section{Model of turning resistance}

While performing turning manoeuvres with a MWC, wheels are generally rolling while swivelling. Hence, the whole resistance acting on a wheel can be split into rolling and swivelling resistances, acting orthogonally (Figure 1). The torque of rolling resistance is explained by a forward shift of the centre of pressure with respect to the theoretical contact point (due to the inelastic properties of the wheel and the ground). This results in a resistant moment at the theoretical contact point which is induced by the normal component of ground reaction force [22]. Previous studies [22, 27-29] expressed the torque of rolling resistance as the product of the rolling resistance parameter $(\lambda)$ (the shift distance) and the normal component of the ground reaction force $R_{N}$ (i.e., the opposite of the weight in case of a lifeless mass):

$$
T_{R R}=\lambda R_{N}
$$

Conversely, during a swivelling motion, the wheel/ground materials first deform and then slip in the contact area, thereby creating a resistant torque. According to the classical works of mechanics [30], the torque of swivelling resistance was modelled by analogy to the torque of rolling resistance, i.e., as the product of a swivelling resistance parameter, $\eta$, and the normal component of the ground reaction force $R_{N}$ :

$$
T_{S R}=\eta R_{N}
$$

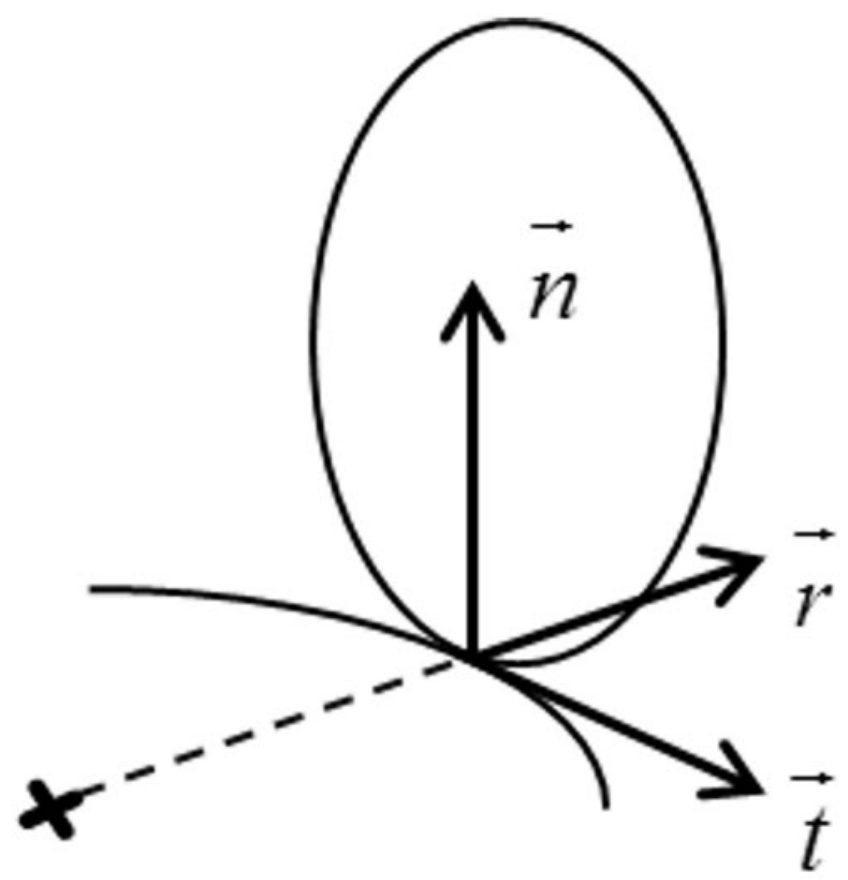

Figure 1. Schema of the local coordinates system with tangential $(t)$, radial $(r)$ and normal (n) components, and centred on the resulting contact point between the wheel and the ground. The torque of rolling resistance acts following the radial direction whereas the torque of swivelling resistance acts following the normal component.

\section{Test bench}

In order to quantify the swivelling resistance parameter $(\eta)$ of a wheel rolling while swivelling, a specific test bench (Figures 2 and 3) was developed. It was composed of a dedicated mechanical device allowing the wheel to be driven in a turning motion in the horizontal plane with a controlled curvature radius, and a six-component force plate (AMTI, BP400600, $100 \mathrm{~Hz}$ ) fixed horizontally to record the mechanical actions (both forces and torques) at the interface between the wheel and the ground. Due to the limited dimension of the force plate, the amount of rotation and the rolling distance varied with the tested curvature radius. However, the device allows curvature radii from 0.1 to $0.4 \mathrm{~m}$ to be tested, with resulting amount of measured rotations ranging from 75 to $160^{\circ}$, and measured rolling distances ranging from 0.25 to $0.60 \mathrm{~m}$.

The mechanical device (Figure 2) was composed of two steering axes linked by a rigid beam of variable length which allowed different curvature radii $\left(r_{c}\right)$ to be imposed. The tested wheel was attached to the device with a fork and was loaded using additional masses applied on the fork. The cylindrical joint on the principal steering axis (Figure 2(B)) allowed the system to adapt to every wheel diameter. Except for the case of pure swivelling (i.e., $r_{c}>0$ ), the turning motion was imposed by moving the beam around the principal steering axis and the wheel automatically aligned tangentially to the imposed circular trajectory. In order to avoid the shimmy phenomenon, a $5 \mathrm{~cm}$ fork trail was used when $r_{c}$ was not null. Considering the motion of pure swivelling (i.e., $r_{c}=0$ ), the principal steering axis was locked, fixing the orientation of the beam. In addition, the wheel was attached to the fork with a specific device allowing the wheel centre to be aligned with the fork steering axis; and resulted in a zero fork trail distance (Figure 2(C)). In this case, the wheel could only rotate around the steering axis of the fork and no rolling motion occurred.

For the identification of the $\eta$ parameter, the torque of swivelling resistance $T_{S R}$ was directly measured through the 


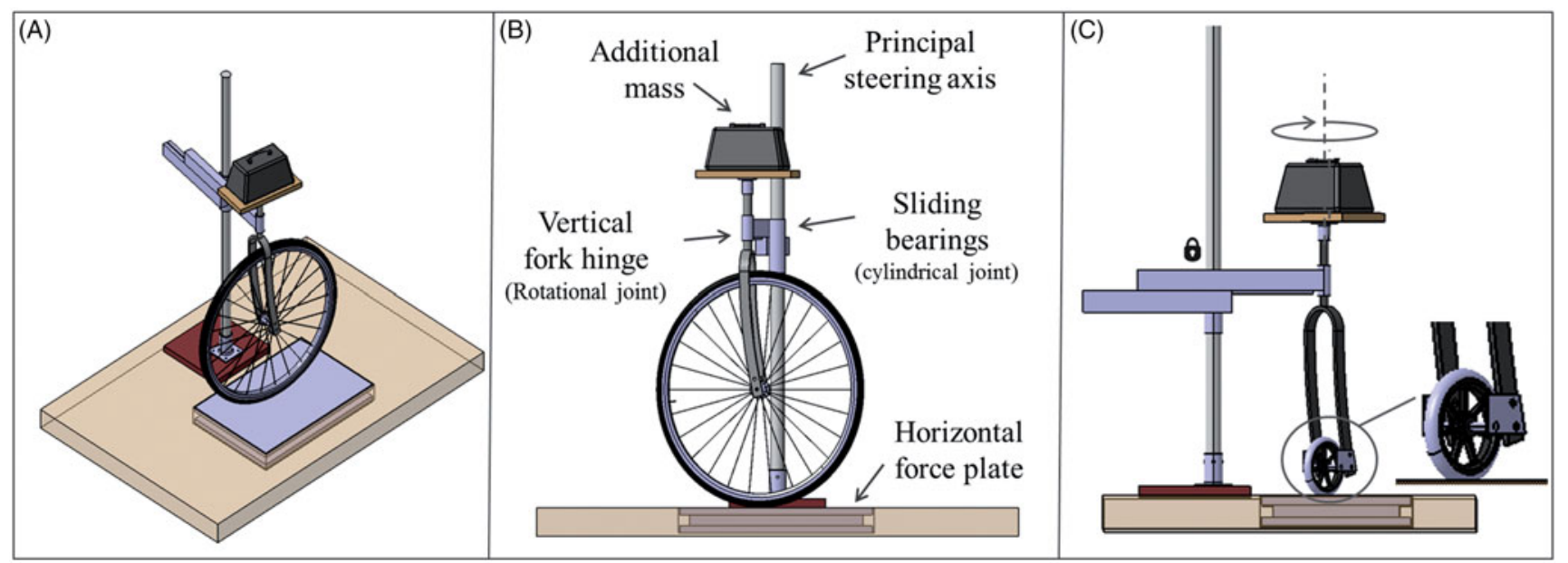

Figure 2. 3-dimensional (3-D) schematic representation of the test bench. (A-B) 3-D isometric and front view during a test of a rear wheel with a curvature radius of $0.3 \mathrm{~m}$; (C) representation of the test of a front caster during a pure swivelling motion with a zoom on the adaptation part allowing to cancel the fork trail distance. During the experiments, the horizontal beam is actuated manually by an operator.

(A)

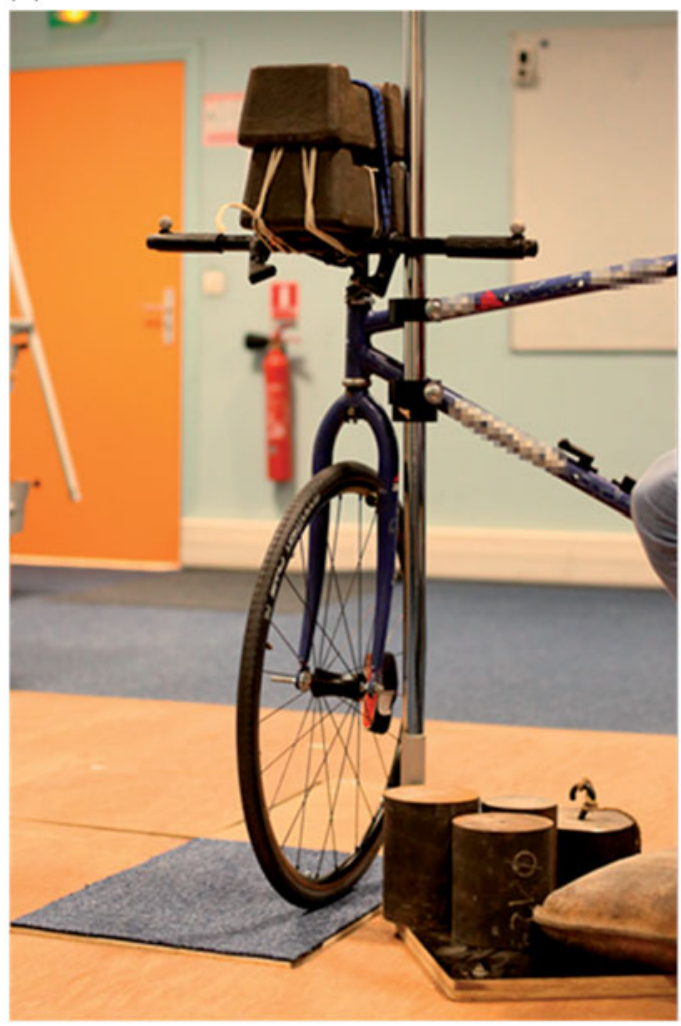

(B)

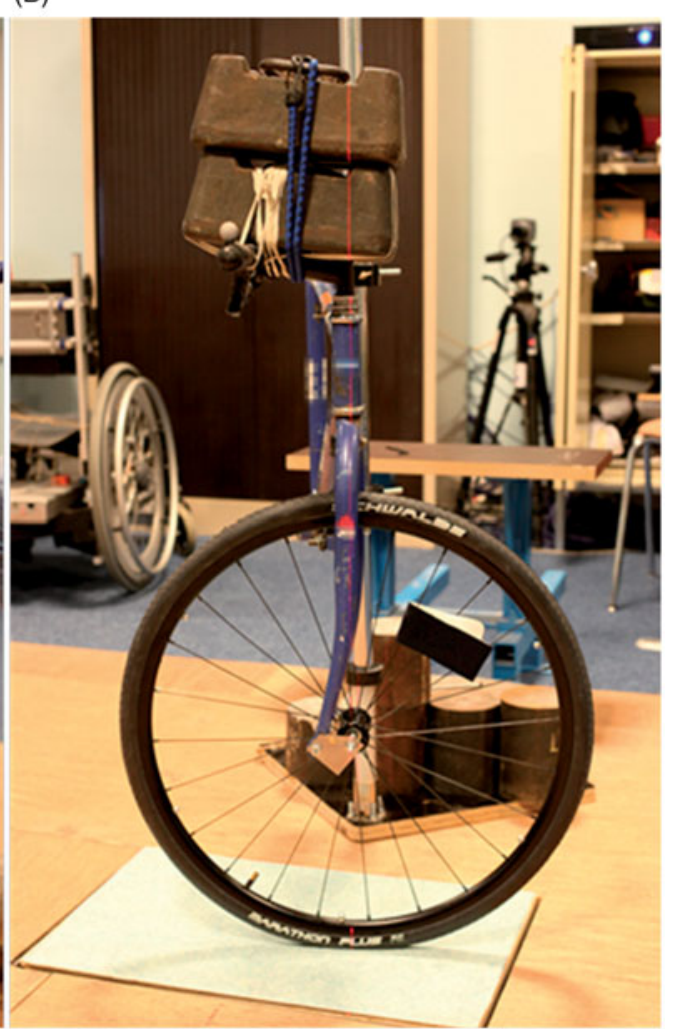

Figure 3. Photographs of the real physical experiment device with (A) $40 \mathrm{~kg}$ of additional mass, $0.1 \mathrm{~m}$ of curvature radius, wheel W1, on carpet and (B) $40 \mathrm{~kg}$ of additional mass, pure swivelling $\left(r_{c}=0\right)$, wheel W1, on linoleum.

six-component force plate, which gave both forces and torques in the same local coordinate systems $\left(F_{x}, F_{y}, F_{z}, T_{O x}, T_{O y}, T_{O z}\right)$ (Figure 4); with $x$ - and $y$-axes defining the horizontal plane, $z$-axis defining the vertical direction, and $\mathrm{O}$ was the origin of the force plate where the torques were expressed. Considering the centre of pressure $\left(C O P\right.$, with coordinates: $\left.x_{C O P}, y_{C O P}, z_{C O P}\right)$ of the wheel on the ground, the torque measured by the force plate $\left(T_{O x}, T_{O y}\right.$ $\left.T_{O Z}\right)$ at its origin was decomposed as:

$$
\left(\begin{array}{c}
T_{O x} \\
T_{O y} \\
T_{O z}
\end{array}\right)=\left(\begin{array}{c}
T_{C O P x} \\
T_{C O P y} \\
T_{C O P z}
\end{array}\right)+\left(\begin{array}{c}
y_{C O P} F_{z}-z_{C O P} F_{y} \\
z_{C O P} F_{x}-x_{C O P} F_{z} \\
x_{C O P} F_{y}-y_{C O P} F_{x}
\end{array}\right)
$$

where $T_{C O P P_{x},} T_{C O P y}, T_{C O P}$ are the three components of the torque applied by the ground on the wheel at the CoP.

From the definition of the $C O P$, and given the nature of the contact between the force plate and the wheel, the local torque acting at the CoP did not have any component following $x$ - and $y$-axes (i.e., $T_{C O P} x=T_{C O P} y=0$ ). This allowed the horizontal components of the CoP to be identified from the first and second components of Equation (3):

$$
x_{C O P}=-\frac{T_{O y}-z_{C O P} F_{x}}{F_{z}} \text { and } y_{C O P}=\frac{T_{O x}-z_{C O P} F_{y}}{F_{z}}
$$




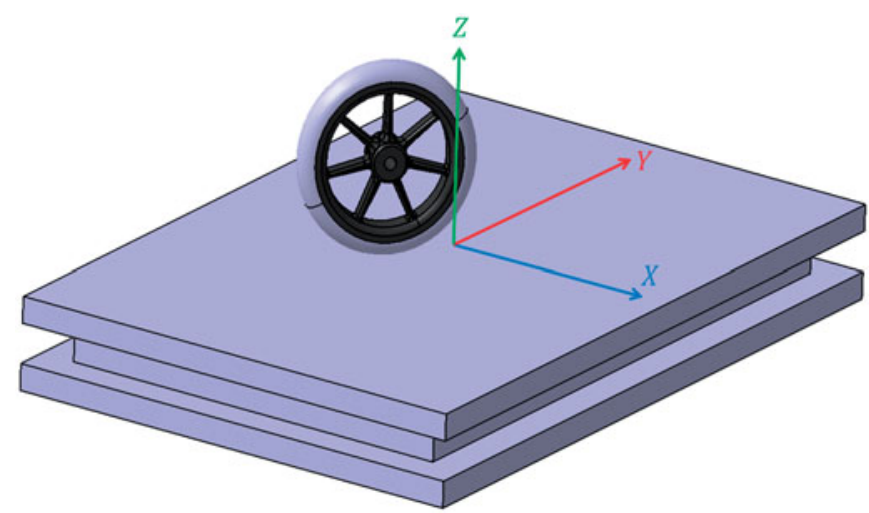

Figure 4. Representation of the force-plate local reference frame in which the centre of pressure is determined.

where $z_{C O P}$ was the height of the contact surface between the wheel and the ground with respect to the origin of the force plate, and was previously known from the force plate datasheet and the thickness of the tested surface.

By reinjecting $x_{C O P}$ and $y_{C O P}$ from Equation (4) in the third component of Equation (3), it became possible to express $T_{\text {CoP }} z$ which was the torque of swivelling resistance $\left(T_{S R}\right)$ :

$$
T_{S R}=T_{C O P z}=T_{O z}-x_{C O P} F_{y}+y_{C o P} F_{X}
$$

Finally, based on Equation (2) and considering $F_{z}=R_{N}$ it became possible to calculate $\eta$ from force plate data only.

\section{Data processing}

For each trial, raw data provided by the force plate were smoothed (moving average, five values) and the resulting data were used to determine both the instantaneous $\mathrm{COP}$ coordinates $\left(x_{C O P}\right.$ and $\left.y_{C O P}\right)$ and the torque of swivelling resistance $\left(T_{S R}\right)$ (Equations 4 and 5). Then, the instantaneous curvature radii $r_{c}$ of the COP trajectory were computed using a three points method with a sliding window. This step allowed the actual $r_{c}$ to be checked with respect to the one imposed by the setup. Finally, the $T_{S R}$ mean value of the trial was computed.

\section{Experiments}

In order to determine the respective impact of each type of wheel, surface, load and curvature radius $\left(r_{c}\right)$, a full factorial design experiment was performed using seven different wheels (Table 1, Figure 5), three different surfaces (plywood panel, linoleum and $3 \mathrm{~mm}$ loop pile carpet), five $r_{c}$ values (from 0 to $0.4 \mathrm{~m}$ by $0.1 \mathrm{~m}$ increment) and two loading conditions (with 20 and $40 \mathrm{~kg}$ of additional mass). The loading conditions were selected to be in accordance with the loading context of a single front and rear wheel during the use of a MWC. The effect of tire inflation was investigated through testing a same wheel inflated both at 10 and 50 psi (W2 and W3 in Table 1). Five trials were performed for each of the 210 combinations, resulting in 1050 trials in total.

\section{Data analysis}

Swivelling resistance parameters, $\eta$, were computed for every trial. For each combination, potential outliers were identified using the Tukey outlier automatic detection technique (data outside the 1.5 interquartile range) and the average value was then calculated on the remaining trials. Then, a factorial design methodology was
Table 1. Characteristics of the tested front and rear wheels.

\begin{tabular}{llccc}
\hline Wheel & Type & $\begin{array}{c}\text { Diameter } \\
(\mathrm{m})\end{array}$ & $\begin{array}{c}\text { Width } \\
\text { (in.) }\end{array}$ & $\begin{array}{c}\text { Pressure } \\
\text { (psi) }\end{array}$ \\
\hline W1 - Rear wheel & Pneumatic & 0.60 & 1 & 110 \\
W2 - rear wheel & Pneumatic & 0.61 & $1-3 / 8$ & 50 \\
W3 - rear wheel & Pneumatic & 0.61 & $1-3 / 8$ & 10 \\
W4 - rear wheel & Solid & 0.61 & $1-3 / 8$ & $/$ \\
W5 - Standard caster & Solid & 0.20 & 1,18 & $/$ \\
W6 - Soft roll caster & Solid & 0.15 & 1,18 & $/$ \\
W7 - Roller caster & Solid & 0.10 & 1 & $/$ \\
\hline
\end{tabular}

used to quantify the effect of the different factors. First, the mean $\eta$ parameter of the whole data set was computed. Then, for every element (17 elements in total: three floors, seven wheels, five curvature radii and two loads) the mean $\eta$ parameter for all configurations involving this element was determined. For example, for the floor surfaces, the mean values were calculated for plywood panel (average value of all $\eta$ parameters obtained when the floor surface was plywood panel), then for linoleum and finally for carpet.

\section{Uncertainties evaluation}

Repeatability was assessed by computing the standard deviation (SD) of the $\eta$ value within every one of the 210 measurement series. Mean and extrema were determined.

Reliability of the identified $\eta$ parameters is strongly dependent on the force plate reliability, and particularly on the determination of the CoP location (see Equation (4)). To evaluate the effect of potential force plate inaccuracies, a $5 \mathrm{~mm}$ location error was introduced on the COP for four conditions $(+x,-x,+y,-y)$. This was done for all trials and the $\eta$ parameters were recalculated. Then, both the maximal and the root mean square errors (RMSE) between measured and simulated parameters were computed.

The reproducibility was assessed by performing eight series of five trials with the same conditions (W2, plywood panel, $+20 \mathrm{~kg}$ and $r_{c}=0.4 \mathrm{~m}$ ). Between every series, the mechanical device was disassembled then reassembled. The average $\eta$ value was computed for each series and the standard deviation $(S D)$ of the eight average values was considered as the reproducibility error.

Finally, the overall uncertainty variance $\left(\varepsilon^{2}\right)$ was estimated by the sum of the square values of the reliability RMSE and reproducibility $S D$; and the overall uncertainty $(\varepsilon)$ was defined by the square root of the overall uncertainty variance.

\section{Results}

\section{Uncertainties evaluation}

For the repeatability assessment, intra-series $S D$ was $1.0 \mathrm{~mm}$ on average and ranged between 0.5 and $2.5 \mathrm{~mm}$. The sensitivity analysis showed that perturbing the $C O P$ location by $5 \mathrm{~mm}$ resulted in a RMSE of $0.2 \mathrm{~mm}$ on the $\eta$ parameter and did not exceed $2.5 \mathrm{~mm}$ on the whole dataset. Regarding the reproducibility analysis, the series average values ranged from 5.8 to $7.6 \mathrm{~mm}(\Delta: 1.8 \mathrm{~mm})$ for a same condition with a SD of $0.6 \mathrm{~mm}$. Finally, the overall uncertainty $(\varepsilon)$ was $0.63 \mathrm{~mm}$.

\section{Factorial experiments}

In the different series, $R_{N}$ was around $250 \mathrm{~N}$ (SD: $14 \mathrm{~N}$ ) for an additional mass of $20 \mathrm{~kg}$ and $450 \mathrm{~N}$ (SD: $23 \mathrm{~N}$ ) for an additional mass of $40 \mathrm{~kg}$. Overall, $\mathrm{T}_{\mathrm{SR}}$ (average value of each series) ranged from 0.03 to $14.5 \mathrm{Nm}$ and $\eta$ ranged from 0.2 to $37.3 \mathrm{~mm}$. 

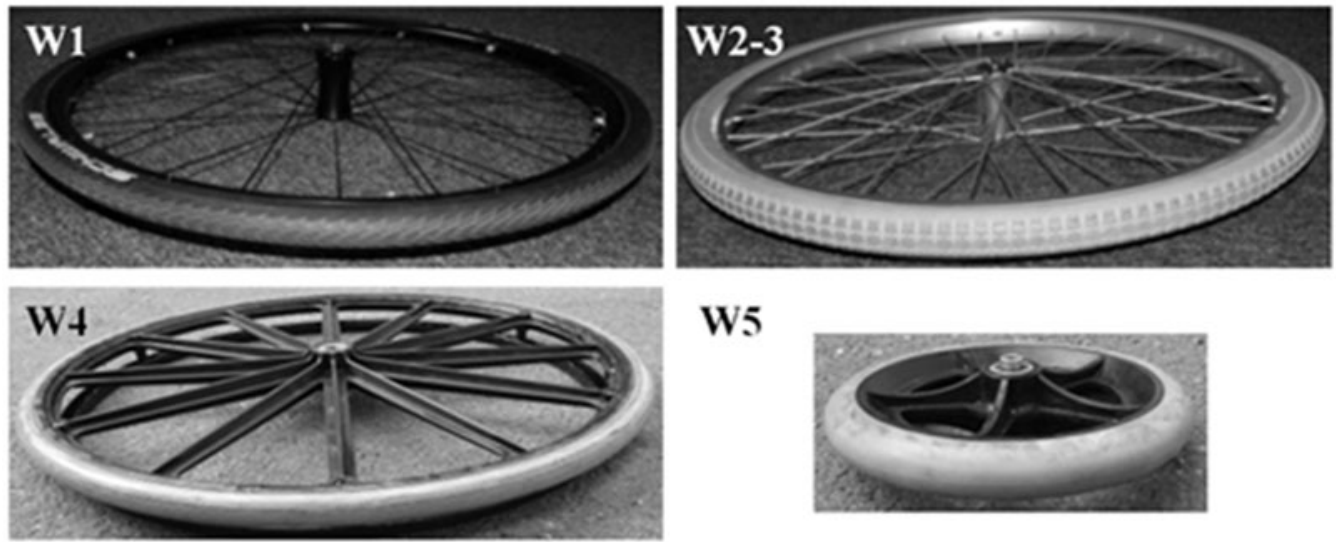

W5
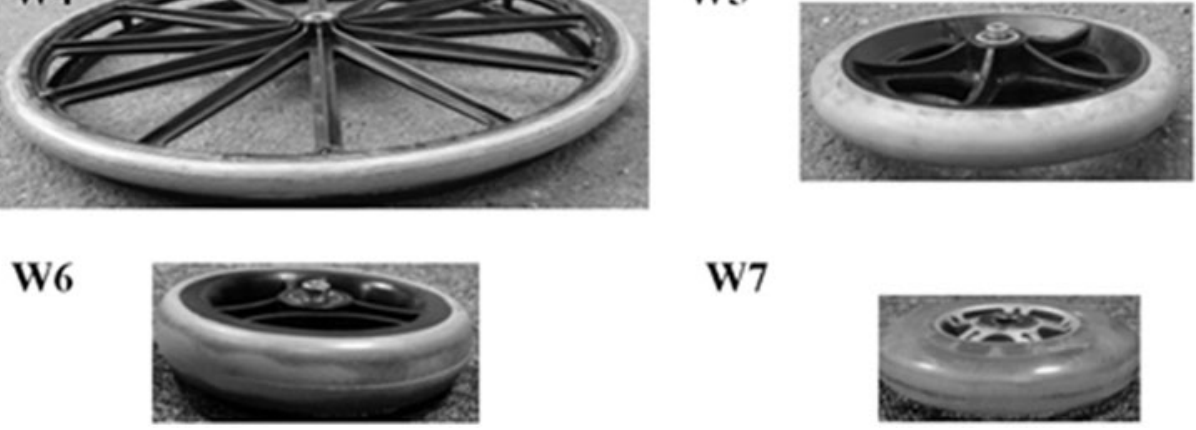

W7

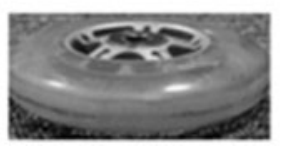

Figure 5. Photographs of the seven wheels tested during the experiments.

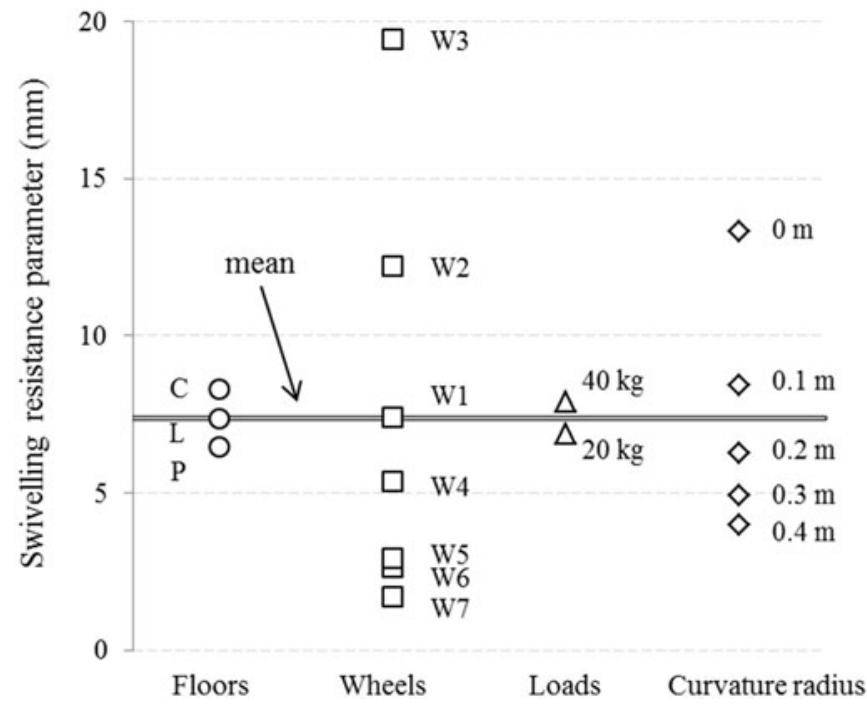

Figure 6. Mean results for swivelling resistance parameters $(\eta)$ according to the different factors of influence. Floors: (C) Carpet, (L) Linoleum, (P) Plywood Wheels: (W1) rear wheel $110 \mathrm{psi}$ (W2) rear wheel $50 \mathrm{psi}$, (W3) rear wheel $10 \mathrm{psi}$, (W4) rear wheel solid tire, (W5) standard castor, (W6) soft roll castor and (W7) roller castor.

The swivelling resistance parameters, according to the different factors (surface, wheel, load and $r_{c}$ ), are presented in Figure 6. On average, for the 210 configurations, $\eta$ was $7.4 \mathrm{~mm}$. Among the different factors, the wheel type was the most influential with $\eta$ parameters ranging from $2.3 \mathrm{~mm}$ for the roller castor (W7) to $19.4 \mathrm{~mm}$ for the deflated wheel (W3). All front castors showed similar $\eta$ values, close to $2.5 \mathrm{~mm}$. Rear wheels showed higher $\eta$ values, ranging from $5.4 \mathrm{~mm}$ for the solid tire (W4) to $12.2 \mathrm{~mm}$ for the pneumatic W2. Tire inflation also showed a significant effect, with $\eta$ values increasing from 12.2 to $19.4 \mathrm{~mm}$ when the tire pressure was decreased from 50 to 10 psi (W2 vs W3). The second factor of influence was the curvature radius of the trajectory: the lower the radius, the higher the $\eta$ value. When $r_{c}$ increased from 0 to $0.4 \mathrm{~m}, \eta$ decreased from 13.3 to $4.0 \mathrm{~mm}$. Besides, this decrease was all the more important when the radius was small. Indeed, the decrease of $\eta$ was higher in the $r_{c}$ range of $0 \mathrm{~m}$ (pure swivelling) to $0.1 \mathrm{~m}(\Delta \eta=-5 \mathrm{~mm})$ than in the range of $0.1 \mathrm{~m}$ to
Table 2. Swivelling resistance parameters ( $\eta$, in $\mathrm{mm}$ ) depending on the floor surface, the wheel type and the curvature radius.

\begin{tabular}{lrrrrr}
\hline Curvature radius (m) & 0 & 0.1 & 0.2 & 0.3 & 0.4 \\
\hline Plywood & & & & & \\
W1 - rear wheel 110 psi & 13.3 & 7.6 & 5.3 & 3.5 & 2.7 \\
W2 - rear wheel 50 psi & 12.6 & 11.3 & 11.5 & 9.6 & 8.0 \\
W3 - rear wheel 10 psi & 22.0 & 19.0 & 15.3 & 15.2 & 14.2 \\
W4 - rear wheel solid & 8.1 & 5.5 & 3.7 & 3.2 & 2.5 \\
W5 - Standard caster & 6.7 & 2.7 & 1.6 & 1.0 & 0.7 \\
W6 - Soft roll & 6.0 & 2.4 & 1.6 & 0.9 & 0.6 \\
W7 - Roller caster & 3.5 & 2.2 & 1.3 & 0.8 & 0.5 \\
Linoleum & & & & & \\
W1 - rear wheel 110 psi & 14.2 & 7.3 & 5.6 & 3.9 & 3.1 \\
W2 - rear wheel 50 psi & 21.1 & 12.3 & 10.7 & 9.1 & 7.8 \\
W3 - rear wheel 10 psi & 33.7 & 20.9 & 16.9 & 11.9 & 10.8 \\
W4 - rear wheel solid & 9.7 & 6.4 & 5.0 & 4.3 & 3.1 \\
W5 - Standard caster & 9.5 & 3.0 & 1.8 & 1.6 & 0.8 \\
W6 - Soft roll & 8.3 & 3.1 & 1.6 & 1.0 & 1.1 \\
W7 - Roller caster & 4.5 & 1.6 & 0.8 & 0.5 & 0.2 \\
Carpet & & & & & \\
W1 - rear wheel 110 psi & 18.8 & 12.1 & 6.7 & 4.1 & 3.2 \\
W2 - rear wheel 50 psi & 21.2 & 18.3 & 12.3 & 10.2 & 7.6 \\
W3 - rear wheel 10 psi & 33.4 & 27.2 & 21.3 & 16.6 & 12.8 \\
W4 - rear wheel solid & 11.8 & 6.9 & 5.0 & 3.6 & 2.1 \\
W5 - Standard caster & 8.6 & 2.5 & 1.5 & 1.1 & 0.9 \\
W6 - Soft roll & 7.0 & 3.0 & 1.0 & 0.8 & 0.6 \\
W7 - Roller caster & 5.8 & 1.9 & 1.0 & 0.5 & 0.2 \\
\hline
\end{tabular}

$0.2 \mathrm{~m}(\Delta \eta=-1.8 \mathrm{~mm})$. The floor surface was the third most influential factor with $\eta$ parameters ranging from $6.5 \mathrm{~mm}$ for plywood to $8.3 \mathrm{~mm}$ for carpet. Finally, the effect of load, with $\eta$ parameters varying from 6.9 to $7.9 \mathrm{~mm}$ when increasing the load from 250 to $450 \mathrm{~N}$, appeared negligible compared to the other factors. Because of this low influence, only average values of $\eta$ obtained for loads of 250 and $450 \mathrm{~N}$ were reported in Table 2.

Figure 7 represents the effect of $r_{c}$ for two typical wheels (W1 and W6). If the global trend exhibited a decrease with $r_{c}$, the effect was more or less pronounced depending on the wheel and floor types. For instance, in Figure 7, the decrease of $r_{c}$ from 0 to $0.4 \mathrm{~m}$ resulted in $\Delta \eta=-7 \mathrm{~mm}$ for the soft roll castor whereas it reached $-15 \mathrm{~mm}$ for the rear wheel pneumatic tire (on carpet surface). Overall, the higher the $\eta$ value in pure swivelling conditions $\left(r_{c}=0\right)$, the higher the decrease with the curvature radius. 


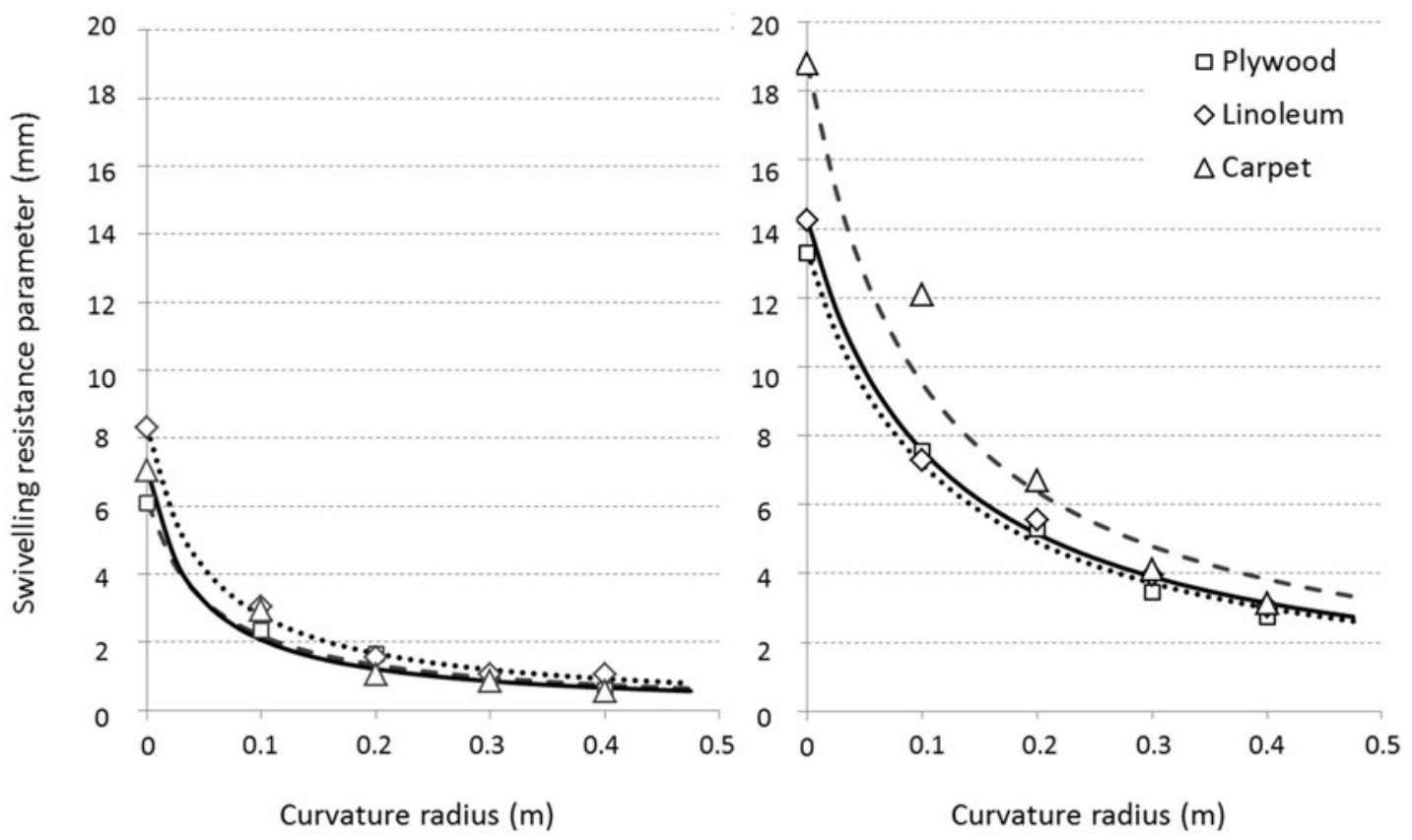

Figure 7. Effect of the curvature radius for soft roll castor (W6) (left) and 1" rear wheel pneumatic tire inflated at 110 psi (W1) (right) for three indoor surfaces. Marks are experimental results. Curves are obtained from the models (Equation (6) combined with Table 3).

Table 3. Coefficients $a$ and $b(a / b)$ to be used in Equation (7) for all combinations of wheel and floor types.

\begin{tabular}{lccc}
\hline & Plywood & Linoleum & Carpet \\
\hline W1 - rear wheel 110 psi & $645 / 75^{(2)}$ & $619 / 70^{(1)}$ & $519 / 53^{(5)}$ \\
W2 - rear wheel 50 psi & $90 / 78^{(3)}$ & $245 / 48^{(4)}$ & $157 / 48^{(6)}$ \\
W3 - rear wheel 10 psi & $76 / 46^{(4)}$ & $167 / 30^{(3)}$ & $94 / 30^{(6)}$ \\
W4 - rear wheel solid & $655 / 125^{(1)}$ & $497 / 104^{(1)}$ & $693 / 86^{(2)}$ \\
W5 - Standard caster & $2680 / 149^{(1)}$ & $2290 / 105^{(1)}$ & $2660 / 117^{(1)}$ \\
W6 - Soft roll & $2930 / 164^{(1)}$ & $2390 / 120^{(1)}$ & $3410 / 142^{(2)}$ \\
W7 - Roller caster & $2790 / 286^{(1)}$ & $6230 / 227^{(1)}$ & $6450 / 174^{(2)}$ \\
\hline
\end{tabular}

$\eta$ and $r_{c}$ are reported in metres. RMSE levels (in $\mathrm{mm}$ ) are presented between brackets: (1) $\leq 0.25$, (2) $0.26-0.50$, (3) $0.51-0.75$, (4) $0.76-1.00$, (5) $1.01-1.25$, (6) $>1.25$.

\section{Experimental models}

For assessment purposes of the swivelling resistance, the evolution of $\eta$ according to $r_{c}$ was modelled using the following analytical function, neglecting the effect of the load:

$$
\eta=\frac{1}{a r_{c}+b}
$$

where $a$ and $b$ are two coefficients allowing to fit experimental data (Table 2). In this expression, the first coefficient (a) is related to the decrease of the $\eta$ parameter with respect to the curvature radius: the higher this coefficient, the higher the decrease. The second coefficient (b) represents $1 / \eta_{0}$, which is the inverse of the $\eta$ parameter obtained in the pure swivelling condition. Hence, high $b$ coefficient value implies a low $\eta$ parameter in pure swivelling. Coefficients for every combination of wheel and floor type are reported in Table 3. Finally, the RMSE between the measured and assessed $\eta$ values was $0.5 \mathrm{~mm}$ on average (range: 0.06-1.35 mm). Results were better on plywood (mean: $0.34 \mathrm{~mm}$, range: $0.16-0.77 \mathrm{~mm}$ ) and linoleum surfaces (mean: $0.37 \mathrm{~mm}$, range: $0.17-0.91 \mathrm{~mm}$ ) than on a carpet surface (mean: $0.73 \mathrm{~mm}$, range: $0.06-1.35 \mathrm{~mm}$ ). In a similar manner, results were better for solid wheels (W4, W5, W6 and W7) than these obtained for pneumatic ones (W1, W2 and W3). The most important inaccuracies $(2.6 \mathrm{~mm})$ were found for $\mathrm{W} 1$ and $\mathrm{W} 2$ on carpet with $r_{c}=0.1 \mathrm{~m}$.

\section{Discussion}

\section{Uncertainties evaluation}

The result of the repeatability evaluation (mean $S D=1 \mathrm{~mm}$ ) showed the necessity of performing several measurements for each condition and to select the average $\eta$ value in order to minimise the uncertainty. The sensitivity of the $\eta$ parameter to force plate measurement uncertainties resulted in a RMSE of $0.2 \mathrm{~mm}$ and reassembling the mechanical device prior to each series had a limited impact on the reproducibility (SD: $0.6 \mathrm{~mm}$ ). Finally, considering the overall uncertainty $(\eta=0.6 \mathrm{~mm})$, inter-series differences below $0.6 \mathrm{~mm}$ should be reservedly interpreted.

\section{Factorial experiments}

A full factorial experiment was performed involving seven wheels, three surfaces, five curvature radii and two loads. This study identified the wheel type as the primary factor of influence on swivelling resistance. Results showed that $\eta$ parameters were lower for front castors than for rear wheels, which was already found for rolling resistance parameters $(\lambda)$ [22]. However, the rolling resistance acting on the MWC can be assimilated to a force that is a function of the rolling resistance factor $[15,22,28]$, which is the ratio between the $\lambda$ parameter and the wheel radius. Therefore, for a given $\lambda$, the higher the wheel radius, the lower the resistance. Thus, the rolling resistance of the rear wheels was significantly lower than that of the front castors. Conversely, the swivelling resistance is a torque that is directly linked to the $\eta$ parameter (Equation (2). Therefore, the swivelling resistance remains higher on rear wheels than on front caster. In addition, because the rear wheels are generally more loaded than front castors, the choice of the rear wheel characteristics can be crucial to improve MWC user mobility.

On the one hand, the $\eta$ values of front castors were close even if roller castors exhibited the lowest resistance to swivelling motion, followed by soft roll and standard castors. This ranking was consistent with previous results reported on rolling resistance parameters [22]. On the other hand, large differences were found 
between the rear wheel types. Surprisingly, solid tires exhibited lower swivelling resistance than pneumatic ones. This result is in contradiction with results found on rolling resistance parameters $[11,22]$. However, differences in tread design may explain, at least partially, this unexpected result. Further investigations to quantify the effect of tread design should be done to distinguish the respective effects of tread design and wheel type. Tire inflation also exhibited a significant effect on swivelling resistance as it was already shown for rolling resistance [14]. In this study, swivelling resistance was increased by $50 \%$ by decreasing the tire pressure from 50 to $10 \mathrm{psi}$. Maintenance of rear wheel tire inflation is thus a simple and not-expensive way to support MWC user mobility.

As expected, the effect of the surface on swivelling resistance was not negligible. Indeed, larger $\eta$ parameter values were obtained for carpet floor surfaces than for tile surfaces (linoleum and plywood panel). This result is consistent with existing literature on turning [25] and rolling [22] resistances. Hence, for both straight and curvilinear trajectories, resistance to motion is increased by a carpet surface and this result confirms the importance of limiting carpeted surfaces to support MWC user mobility. Between tile surfaces, higher $\eta$ values were found on linoleum as opposed to plywood surface. This could be explained by both the higher deformation of the linoleum and the higher adherence properties between wheel and linoleum materials.

An important goal of this study was to quantify the effect of the curvature radius on $\eta$ parameters. As expected, this factor had an important influence. Indeed, in comparison with the pure swivelling condition, the $\eta$ value was divided by two when the curvature radius reached $0.1 \mathrm{~m}$; and was divided by more than four when it reached $0.4 \mathrm{~m}$, which confirms previous literature assumptions [25,27] and results [20].

Finally, load appeared to have a limited effect on $\eta$ parameters, at least in the range of 250 to $450 \mathrm{~N}(\Delta \mu=1 \mathrm{~mm})$. This limited effect allowed simplified presentation of the results (Table 2 ) and models (Table 3), which appeared as an acceptable trade-off for model simplicity and prediction accuracy with predictive equations of $\eta$ parameters only depending on the types of wheels and surfaces. But, if $\eta$ can be assumed to be insensitive to load, the torque of swivelling resistance remains directly related to the applied load (see Equation (2)).

Nonetheless, results of this factorial experiment are still subjected to some limitations. First, the turning motion was performed manually by an experimenter without automatic control of the velocity. However, considering the range of rolling and swivelling velocities in MWC locomotion, the effect of velocity can be assumed to be negligible. Second, if the loads were chosen to be in accordance to the classical loading context of MWC wheels, the experiments did not included extreme conditions with very low/high loads. Extrapolation of the results to these extreme conditions would thus be done with some reserve.

\section{Experimental models}

The experimental models allow the $\eta$ value to be assessed with respect to the instantaneous wheel trajectory curvature radius $\left(r_{c}\right)$. These models were provided for every tested wheel/surface combination. The RMSE showed a better agreement between model prediction and experimental observations for all front casters and for the solid rear wheel than for the pneumatic rear wheels on all surfaces. Assessment of the actual $\eta$ value appeared to be less reliable for the pneumatic rear wheels, even if it remained acceptable on plywood and linoleum. For these wheels on a carpet surface, the $\eta$ value in pure swivelling was correct by definition (Equation (6), but the model tended to underestimate $\eta$ until the curvature radius reached $0.2 \mathrm{~m}$ and to then overestimate it. The discrepancy observed between prediction and experimental data for pneumatic wheels could be decreased by a more complex model. However, the proposed model already provides acceptable results considering the field of application for which it was intended for. In addition, the highest error $(2.6 \mathrm{~mm})$ remains noticeably lower than the previous estimate from literature [25]. Hence, all the provided models (combining Equation (7) and Table 3) can be used for the assessment of wheels swivelling resistance.

\section{Conclusion}

This study aimed at providing quantified data of swivelling resistance parameters for assessment purposes depending on both floor surface and wheel type. The effects of the load and the curvature radius were also investigated. For that purpose, three surfaces, seven wheels, two loads and five curvature radii were tested through a full factorial design experiment.

The wheel type was found to be the most influential factor with important differences between front and rear wheels. Rear wheels also exhibited large differences between them whereas front wheels showed very similar values. However, ranking of wheel type in term of swivelling resistance was not the same as that was previously found for rolling resistance. Hence, depending on the loading configuration of the MWC and the kind of manoeuvers, the optimal set of wheels could be different and further studies need to be performed to clarify this question. The floor surface showed an expected impact on swivelling resistance but this effect remained limited when compared to the one of the wheel type. As for rolling resistance, less swivelling resistance is applied on tile surfaces than on a carpet surface. Hence, regardless the kind of MWC manoeuvers, carpet surfaces would be avoided to support MWC user mobility. The curvature radius of the wheel trajectory also showed a significant effect with swivelling resistance parameters divided by four when the curvature radius increased from 0 to $0.4 \mathrm{~m}$. However, as it was previously found [20], this decrease was not linear.

Results of the full factorial design experiment allowed to present a model of swivelling resistance parameters according to the curvature radius. This was done from a rational function based on two coefficients, specific to every wheel/surface combination. The reliability of these models to predict experimental data was interesting, especially when they are compared to results obtained from previous literature values. The predictive models of swivelling resistance parameters presented in this paper can be used to assess energy loss during wheelchair daily activities, allowing the benefits of wheel choices, covering surface, MWC adjustments, or apartment/building accommodations to be evaluated. They can also be used to provide MWC simulators with realistic control instructions for the reproduction of the effect of different surfaces, wheel types or ways to perform a turning motion (choice of the curvature radius).

\section{Disclosure statement}

No potential conflict of interest was reported by the authors.

\section{ORCID}

Joseph Bascou (D) http://orcid.org/0000-0001-5290-8158 
Hélène Pillet iD http://orcid.org/0000-0002-0263-5910

Christophe Sauret (D) http://orcid.org/0000-0002-6196-2698

\section{References}

[1] Brault MW. Americans with disabilities: 2010 household economic studies. US Census Bur. 2012;423:1-24.

[2] Vignier N, Ravaud JF, Winance $M$, et al. Demographics of wheelchair users in France: results of national communitybased handicaps-incapacités-dépendance surveys. Acta Derm Venereol. 2008;40(3):231-239.

[3] Finley MA, Rodgers MM. Prevalence and identification of shoulder pathology in athletic and nonathletic wheelchair users with shoulder pain: a pilot study. JRRD. 2004;41(3B): 395-402.

[4] Mercer JL, Boninger M, Koontz A, et al. Shoulder joint kinetics and pathology in manual wheelchair users. Clin Biomech. 2006;21(8):781-789.

[5] De Groot S, Veeger HEJ, Hollander AP, et al. Consequence of feedback-based learning of an effective hand rim wheelchair force production on mechanical efficiency. Clin Biomech. 2002;17(3):219-226.

[6] Guo L, Kwarciak AM, Rodriguez R, et al. Calidation of a biofeedback system for wheelchair propulsion training. Rehabil Res Pract. 2011;2011:590780.

[7] Chénier F, Bigras P, Aissaoui R. A new wheelchair ergometer designed as an admittance-controlled haptic robot. IEEE/ASME Trans Mechatron. 2014;19(1):321-328.

[8] Blouin $M$, Lalumière $M$, Gagnon $\mathrm{DH}$, et al. Characterization of the immediate effect of a training session on a manual wheelchair simulator with haptic biofeedback: towards more effective propulsion. IEEE Trans Neural Syst Rehabil Eng. 2015;23(1):104-115.

[9] Leving MT, Vegter R, Hartog J, et al. Effects of visual feedback-induced variability on motor learning of handrim wheelchair propulsion. PLoS One. 2015;10(5):e0127311.

[10] Leving MT, Vegter RJK, de Groot S, et al. Effects of variable practice on the motor learning outcomes in manual wheelchair propulsion. J Neuroeng Rehabil. 2016;13(1):100-113.

[11] Frank TG, Abel EW. Measurement of the turning, rolling and obstacle resistance of wheelchair castor wheels. J Biomed Eng. 1989;11(6):462-466.

[12] Hofstad M, Patterson PE. Modelling the propulsion characteristics of a standard wheelchair. J Rehabil Res Dev. 1994; 31(2):129-137.

[13] Faupin A, Campillo P, Weissland $T$, et al. The effects of rear-wheel camber on the mechanical parameters produced during the wheelchair sprinting of handibasketball athletes. JRRD. 2004;41(3B):421-428.

[14] Sawatzsky BJ, Kim WO, Denison I. The ergonomics of different tyres and tyre pressure during wheelchair propulsion. Ergonomics. 2004;47(14):1475-1783.

[15] Bascou J. Biomechanical analysis to undertand and imprivement of high level tennis wheelchair [doctoral dissertation,
In French], Ecole Doctorale Sciences des Métiers de I'Ingénieur. Paris (France): Arts et Métiers ParisTech; 2012.

[16] De Groot S, Vegter RJK, van der Woude L. Effect of wheelchair mass, tire type and tire pressure on physical strain and wheelchair propulsion technique. Med Eng Phys. 2013; 35(10):1476-1482.

[17] Mason BS, Lemstra M, van der Woude LHV, et al. Influence of wheel configuration on wheelchair basketball performance: wheel stiffness, tyre type and tyre orientation. Med Eng Phys. 2015;37(4):392-399.

[18] Pavlidou E, Kloosterman MG, Buurke JH, et al. Rolling resistance and propulsion efficiency of manual and powerassisted wheelchairs. Med Eng Phys. 2015;37(11): 1105-1110.

[19] Sprigle S, Huang M. Impact of mass and weight distribution on manual wheelchair propulsion torque. Assist Technol. 2015;27(4):226-235.

[20] Teran E, Ueda J. Influence of rolling resistance on manual wheelchair dynamics and mechanical efficiency. Int J Intell Robot Appl. 2017; 1(1):55-73.

[21] Chan FHN, Eshraghi M, Alhazmi MA, et al. The effect of caster types on global rolling resistance in manual wheelchairs on indoor and outdoor surfaces. Assist Technol. 2018;30(4):176-182.

[22] Sauret C, Bascou J, de Saint Rémy N, et al. Assessment of field rolling resistance of manual wheelchairs. JRRD. 2012; 49(1):63-74.

[23] Caspall JJ, Seligsohn E, Dao PV, et al. Changes in inertia and effect on turning effort across different wheelchair configurations. J Rehabil Res Dev. 2013;50(10):1353-1362.

[24] Lin J, Huang M, Sprigle S. Evaluation of wheelchair resistive forces during straight and turning trajectories across different wheelchair configurations using free-wheeling coastdown test. J Rehabil Res Dev. 2015;52(7):763-774.

[25] Kauzlarich JJ, Bruning T, Thacker TG. Wheelchair caster shimmy and turning resistance. J Rehabil Res Dev. 1984; 21(2):15-29.

[26] Bascou J, Pillet $\mathrm{H}$, Kollia $\mathrm{K}$, et al. Turning resistance of a manual wheelchair: a theoretical study. Comput Methods Biomech Biomed Engin. 2014;17(Suppl 1):94-95.

[27] Bascou J, Sauret C, Villa C, et al. Measurement of wheelchair adjustment effects on turning deceleration. Comput Methods Biomech Biomed Engin. 2015;18(Suppl 1): 1882-1883.

[28] Cooper R. A systems approach to the modeling of racing wheelchair propulsion. JRRD. 1990;27(2):151-162.

[29] Sauret C, Vaslin P, Lavaste F, et al. Effects of user's actions on rolling resistance and wheelchair stability during handrim wheelchair propulsion in the field. Med Eng Phys. 2013;35(3):289-297.

[30] Hertz, H. über die Berührung fester elastischer Körper [Collisions of Solid Elastic Bodies]. Journal für die reine und angewandte Mathematik. 1881;92:156-171. 